\title{
Words as windows to thought: The case of object representation
}

\author{
David Barner ${ }^{1}$, Peggy $\mathrm{Li}^{2}$, and Jesse Snedeker ${ }^{2}$ \\ ${ }^{1}$ Department of Psychology, University of California, San Diego \\ ${ }^{2}$ Department of Psychology, Harvard University
}

\begin{abstract}
Languages differ in how they express thought, leading some researchers to conclude that speakers of different languages perceive objects differently. Others, in contrast, argue that words are windows to thought - reflecting its structure without modifying it. Here, we explore the case study of object representation. Studies of Japanese, Chinese, and English indicate that speakers of these languages do not perceive objects differently, despite their grammatical differences. Syntax provides frames for words that can select among meanings without affecting underlying object perception.
\end{abstract}

\section{Keywords}

language and thought; object perception; number; Whorfian hypothesis; mass nouns; count nouns; singular / plural

\begin{abstract}
All infants begin life with a common set of perceptual and cognitive tools, and an ability to learn language. However, the languages they learn differ, not only in how they sound, but also in how they express thought. For example, some languages, like English, have grammatical markers that distinguish countable things from other entities, like non-solid substances (e.g., many cats vs. much milk). Other languages, like Japanese, do not, and instead use identical structures to talk about objects and stuff. Such facts have led researchers to ask whether cross-linguistic differences in grammatical structure might cause corresponding differences in how people think about the world. Do speakers of English perceive objects differently from speakers of Japanese? Or are languages merely windows into the mind, each providing a different view of mental structure without changing how we perceive the world?
\end{abstract}

Since Benjamin Whorf's famous claim that language changes our perception of reality, psychologists have studied the relationship between language and thought in a variety of domains including color perception, spatial representation, and navigation (Gentner \& Goldin-Meadow, 2003). Here, we explore how objects are represented by language, and how object perception is affected by cross-linguistic variation. Over the past 40 years, this question has been a focus of research in psychology, linguistics, philosophy, and anthropology, resulting in a vast body of work (see Pelletier, 2009, for review)

In English, countable objects are often encoded by count nouns. Count nouns can be used in singular and plural forms (a cattsome cats), can occur with numerals (three cats), and can be used with discrete quantifiers (many/severall these cats). In contrast, mass nouns cannot be used with plural marking, numerals, or discrete quantifiers ( $*$ two muds). Most mass nouns

\footnotetext{
${ }^{1}$ Address correspondence to David Barner, Department of Psychology, University of California, San Diego, 9500 Gilman Drive, La Jolla, CA 92093-0109; barner@ucsd.edu.
} 
do not refer to countable things (e.g., milk) although some do (e.g., furniture). Whereas English makes a mass-count distinction, languages like Japanese and Mandarin Chinese do not. Nouns in these languages resemble English mass nouns, because they lack rich number marking and cannot occur directly with numerals. For example, in Mandarin three pencils is expressed as "three units of pencil" (san-zhi-bi), similar to English mass nouns (three pieces of chocolate).

According to the Whorfian hypothesis, sometimes called "linguistic determinism", these grammatical differences should lead to cross-linguistic differences in object perception. Extreme Whorfians, like Quine (1960), have argued that count syntax is necessary for representing objects in language. Similarly, Lucy (1992) argues that in Yucatec (which lacks count syntax), nouns fail to encode objects as countable things. Instead, "Yucatec nouns, lacking such a specification of unit, simply refer to the substance or material composition of an object" (p.89).

\section{WORDS AS WINDOWS}

An alternative to the Whorfian view is that words are like windows into thought- - they reveal its structure but do not modify it. Beneath surface differences in how people talk about objects, there is a universal conception of individuals, which is common to speakers of all languages. By this view, language does not transform non-linguistic representations. Similarly, we do not believe that linguistic structures are fully determined by universal conceptual structure. Instead, we take a middle view: languages differ in how they express thought without affecting how the world is perceived non-linguistically

The universalist view presented here predicts that speakers of different languages should perceive objects identically, regardless of linguistic variation. Consequently, the meanings of nouns should not be affected by whether the language has count syntax; number marking should not be necessary for naming objects, even in English. Also, subtle conceptual distinctions that are expressed by count syntax, like the distinction between singular and plural sets, should be universal and emerge before children learn the corresponding grammatical distinction, not after.

Below, we review recent evidence in favor of each idea. Although researchers sometimes disagree about how to define or measure "thought" and "perception", we show that by any measure language does not affect object representation.

\section{WORDS, OBJECTS, AND LEXICAL STATISTICS}

A key prediction of the Whorfian hypothesis is that speakers of English, a mass-count language, are more likely to treat novel things as objects than speakers of Japanese, which lacks mass-count syntax.

Initial support for this prediction comes from studies using the word-extension task, which tests how children interpret new words. When English-speaking children are taught a name for a novel thing (Look at the blicket!), they typically infer that the word refers to a kind of object and extend it to other objects with the same shape (Figure-1A). In contrast, Japanese children more often interpret the word as referring to the thing's substance (Imai \& Gentner, 1997; see also Lucy, 1992).

These results have led many to conclude that Japanese and English-speaking children perceive objects differently. However, this conclusion rests on the assumption that children in both groups received the same information about novel words. Specifically, we must assume that in English "Look at the blicket" is neutral between mass and count and therefore 
similar to the sentence in Japanese, which lacks mass-count syntax. This is problematic, however, because although "the blicket" could be either mass or count, the two possibilities are not equally likely.

As part of comprehending speech, both adults and children unconsciously assign syntactic structures to words. For example, the meaning of "Mary had a little lamb" depends on the structure assigned to lamb, which is ambiguous in this context. If it's a count noun, then the lamb is Mary's pet. If it's a mass noun then it's her dinner. Similarly, when children hear a novel word like blicket they must decide if it is mass or count. Because count nouns are more frequent than mass nouns in English (Samuelson \& Smith, 1999), children could make use of lexical statistics to infer that the ambiguous word is most likely a count noun (Barner, Inagaki, \& Li, 2009; Li et al., 2009). Also, because all count nouns refer to countable individuals, this inference would allow children to conclude that blicket refers to a kind of countable thing. In contrast, since Japanese children are not required to infer masscount status, their judgments should be based solely on physical properties of the items. When presented with a name for a thing whose shape and substance are equally salient, Japanese children should choose randomly, as they indeed do.

Several results suggest that lexical statistics (and not differences in perception) cause crosslinguistic differences in word learning. First, in tasks that directly test perception, crosslinguistic effects disappear. Li, Dunham, and Carey (2009) presented speakers of Japanese, Mandarin, and English with novel objects that varied in shape, substance, and complexity and asked them to rate from 1-7 whether they were objects. In support of the universalist view, ratings did not differ across the three groups, indicating no difference in object perception.

Further evidence comes from Barner et al. (2009), who tested Mandarin-English bilinguals on a word-extension task. Half the bilinguals were tested in English, and half in Mandarin. If language learning causes permanent differences in how speakers perceive objects, then it should not matter what language participants are tested in; only the languages they have learned should matter. However, bilinguals extended words by shape more often when tested in English than when tested in Mandarin, demonstrating that it is linguistic cues, like lexical statistics, that make English speakers more likely to extend novel words to objects, not conceptual differences caused by learning count syntax.

\section{REAL NOUNS}

So far we have focused on word learning and novel objects. But the Whorfian proposal also makes predictions about words with known meanings - i.e., real nouns. If count syntax is needed to refer to individuals (as the Whorfian view suggests), then (1) mass nouns in English should not refer to countable individuals because they lack count syntax, and (2) English counts nouns should be more likely to individuate than equivalent words in Japanese or Chinese. If mass-count syntax affects object perception, it should do so not only for novel objects, but also for real nouns and their referents.

We tested the first prediction by exploring how English speakers interpret words like furniture and jewelry, which are used as mass nouns (Barner \& Snedeker, 2005). Four decades of research have debated whether such words encode their referents as objects or unindividuated masses, given that they are mass nouns. We tested this question using a quantity-judgment task (Figure-1B). English-speaking adults and 4-year-olds were shown two characters who had objects of the same kind (e.g., cups). One had a greater number of items (six small cups) while the other had objects with a greater mass (two giant cups). Participants were then asked who had more (Who has more cups?). When the entities were 
solid objects labeled with a count noun (e.g.,cups) participants chose the person with the greater number of objects, indicating that the word referred to countable things. When the entity was a nonsolid substance described with a substance-mass noun (e.g., ketchup), participants selected the character with the greater volume of the substance, suggesting that the word did not refer to countable individuals. Finally, for object-mass nouns, like furniture, participants based their judgments on number, indicating that the nouns referred to discrete, countable things despite their lack of count syntax.

Crucially, quantity judgments are sensitive to mass-count syntax. For mass-count flexible nouns (e.g., chocolate) participants based their judgments on the number of objects when the words were used in count syntax (who has more strings?), but on volume when they were used in mass syntax (who has more string?). Thus, count syntax can specify individuation when words are ambiguous. Mass syntax, in contrast, is neutral about individuation and leaves meaning up to the noun. As a result, some mass nouns refer to uncountable stuff (ketchup), and others refer to countable individuals (furniture; see Barner \& Snedeker, 2006; Barner, Wagner \& Snedeker, 2008; for evidence regarding novel objects and countable actions).

Extending this, researchers have tested whether the meanings of real nouns are different in languages with count syntax than in those without it. First, they have asked adults to rate whether common nouns refer to objects or substances. These studies find no differences between Japanese and English (Barner et al., 2009; Colunga \& Smith, 2005). Words in both languages are equally likely to refer to objects and to be extended to things with a common shape.

Second, equivalent nouns in Japanese and English have been tested using the quantityjudgment task (Barner et al., 2009). English participants were presented words in explicit mass-count syntax, whereas Japanese speakers did not receive mass-count cues, since their language lacks this distinction. Contrary to the Whorfian prediction, both groups based judgments on number for nouns that typically appear in count syntax in English (e.g., both called six tiny keys "more keys"). For substance-mass nouns both groups based judgments on volume (calling two big portions of sugar "more sugar"). Only nouns that can be used flexibly as either mass or count in English (e.g., chocolate) showed an effect of syntax. English speakers based judgments on number when presented with count syntax (more chocolates), and on volume when presented with mass syntax (more chocolate). Japanese judgments fell squarely between the English mass and count judgments, suggesting that they, like English speakers, perceived these things as ambiguous between being objects and substances.

Finally, studies have compared picture-naming and similarity judgments in Japanese and English (Iwasaki et al., in press). In picture naming, speech errors in both groups reflect English mass-count status; nouns that are classified as count in English are replaced by other nouns that are classified as count in English. Likewise, although English speakers are likely to judge a count noun to be more similar to another count noun (as compared to a mass noun), their judgments do not differ from those of Japanese speakers, suggesting that a common semantics guides judgments, rather than syntax.

These results suggest that all languages can refer to countable things, and that explicit masscount syntax has no effect on how referents are perceived cross-linguistically. The power of mass-count syntax is that it allows speakers to explicitly select from among meanings that would otherwise remain ambiguous, without altering how the things themselves are represented. 


\section{SINGULAR-PLURAL LEARNING}

If syntax selects from pre-existing meanings, rather than creating them, then the concepts underlying mass-count syntax should develop before the syntactic distinction itself. The singular-plural distinction (a cat/some cats) provides a test of this prediction. If language is merely a window to thought, then children should acquire the conceptual distinction between singular and plural sets before learning the syntactic distinction. However, if language restructures how we represent the world, then learning syntax may be a prerequisite for this conceptual leap.

Early in development children fail to distinguish between singular and plural sets (i.e., "one" vs. "more than one"). For example, in a study by Feigenson and Carey (2003), 12-month olds watched as ping-pong balls were placed in a box, and were then allowed to reach into the box and manually search for balls (Figure-1C). On critical trials, the experimenters secretly removed some of the balls. When infants saw 3 balls go in but only retrieved 1 (or 2), they went back and searched extensively for the missing balls, demonstrating that they can keep track of three objects. However, when 4 balls were hidden and 1 was retrieved the infants did not continue looking for the missing balls! This surprising result suggests that infants cannot track sets of four or more and fail to make the basic distinction between "one" and "more than one".

When do children overcome this limitation? Using the manual-search task, we found that English-speaking children begin to distinguish singular and plural sets at around 22 months, the same age they begin producing plural nouns (Barner et al., 2007). In fact, infants were more likely to distinguish singular and plural sets if they produced plural nouns in their speech.

This finding is consistent with the Whorfian view that learning syntax drives conceptual change. However, it is also consistent with the opposite hypothesis: that conceptual change drives syntactic development. To probe these possibilities, we tested infants learning Japanese or Mandarin ( $\mathrm{Li}$ et al., in press). Although these languages lack obligatory plural marking, infants distinguished singular and plural sets at the same age as infants learning English. This suggests that children acquire the conceptual basis for count syntax before acquiring the grammatical distinction. Thought affects language, although language may not affect thought.

\section{OTHER WINDOWS?}

We have focused on how syntax affects object perception and concluded that words, in this case, offer a window into thought. Syntax provides frames for these windows, selecting from the available meanings without affecting how things are perceived. Object representation, however, is only one among many case studies. Other areas of investigation may suggest a more nuanced conclusion. Although language does not likely determine the content of thought, it may nonetheless influence behavior when it is deployed. For example, languages differ in how they label colors, spatial relations, and artifact kinds. These linguistic differences may affect categorization, similarity judgments, and memory of a referent's physical properties or location, especially when language is deployed during tasks (Bowerman, 1996; Kay \& Regier, 2006; Malt et al., 1999). Such effects, however, are not necessarily evidence against the universalist view presented here. Although languages may differ in their semantic distinctions, it remains possible in each case that speakers retain universal perceptual (and conceptual) representations. For example, although the categorical perception of colors differs cross-linguistically in tasks that engage language, color is still perceived by all humans in a universal continuous space (see Roberson et al., 2009). By 
providing humans with a system for labeling and manipulating thoughts, language offers a unique and valuable cognitive tool (Frank et al., 2008). However, even when languages highlight different semantic distinctions, words nonetheless act as windows to a universal system of mental representations.

\section{Acknowledgments}

Thank you to members of the Language and Development Lab, UCSD, and the Lab for Developmental Studies, at Harvard, for their thoughtful comments on earlier versions of this manuscript.

\section{REFERENCES}

Barner D, Inagaki S, Li P. Language, thought, and real nouns. Cognition. 2009; 111:329-344. [PubMed: 19345937]

Barner D, Snedeker J. Quantity judgment and individuation: Evidence that mass nouns count. Cognition. 2005; 97:41-66. [PubMed: 16139586]

Barner D, Snedeker J. Children's early understanding of mass-count syntax: Individuations, lexical content, and the number asymmetry hypothesis. Language Learning and Development. 2006; 2(3): 163-194.

Barner D, Thalwitz D, Wood J, Yang S, Carey S. On the relation between the acquisition of singularplural morpho-syntax and the conceptual distinction between one and more than one. Developmental Science. 2007; 10(3):365-373. [PubMed: 17444976]

Barner D, Wagner L, Snedeker J. Events and the ontology of individuals: Verbs as a source of individuating mass and count nouns. Cognition. 2008; 106:805-832. [PubMed: 17582395]

Bowerman, M. Learning how to structure space for language: A cross-linguistic perspective. In: Bloom, P.; Peterson, MA.; Nadel, L.; Garrett, MF., editors. Language and space. MIT Press; Cambridge, MA: 1996. p. 385-436.

Colunga, E.; Smith, LB. The emergence of abstract ideas: Evidence from networks and babies. In: Saitta, L., editor. Philosophical Transactions by the Royal Society B. Theme Issue: 'The abstraction paths: from experience to concept'. 2003. p. 1205-1214.

Feigenson L, Carey S. Tracking individuals via object-files: Evidence from infants' manual search. Developmental Science. 2003; 6:568-584.

Frank MC, Everett DL, Fedorenko E, Gibson E. Number as a cognitive technology: Evidence from Pirahã language and cognition. Cognition. 2008; 108:819-824. [PubMed: 18547557]

Imai M, Gentner D. A crosslinguistic study of early word meaning: Universal ontology and linguistic influence. Cognition. 1997; 62:169-200. [PubMed: 9141906]

Iwasaki N, Vinson D, Vigliocco G. Does the grammatical count/mass distinction affect semantic representations? Evidence from experiments in English and Japanese. Language and Cognitive Processes. in press.

Kay P, Regier T. Language, Thought and Color: recent developments. Trends in Cognitive Science. 2006; 10:51-54.

Li P, Dunham Y, Carey S. Of substance: The nature of language effects on construal. Cognitive Psychology. 2009; 58:487-524. [PubMed: 19230873]

Li P, Ogura T, Barner D, Yang S-J, Carey S. Does the distinction between singular and plural sets depend on language? Developmental Psychology. in press.

Lucy, J. Grammatical categories and cognition: A case study of the linguistic relativity hypothesis. Cambridge University Press; Cambridge: 1992.

Malt B, Sloman S, Gennari S, Shi M, Wang Y. Knowing versus Naming: similarity and Linguistic Categorization of Artifacts. Journal of Memory and Language. 1999; 40:230-262.

Pelletier, F. New Directions in Cognitive Science. Vol. 12. Oxford University Press; New York: 2009. Kinds, things, and stuff: Concepts of generics and mass terms.

Roberson D, Hanley J, Pak H. Thresholds for color discrimination in English and Korean speakers. Cognition. 2009; 112:482-487. [PubMed: 19619872] 
Samuelson L, Smith L. Early noun vocabularies: Do ontology, category structure and syntax correspond? Cognition. 1999; 73:1-33. [PubMed: 10536222]

Quine, WVO. Word and object. MIT Press; Cambridge, MA: 1960.

\section{RECOMMENDED READINGS}

Gentner, D.; Boroditsky, L. Individuation, relativity and early word learning. In: Bowerman, M.; Levinson, S., editors. Language acquisition and conceptual development. Cambridge University Press; Cambridge, UK: 2001. p. 215-256.A modern classic that discusses early noun learning across different languages, and that argues for Whorfian effects

Gleitman, L.; Papafragou, A. Language and thought. In: Holyoak, K.; Morrison, R., editors. Cambridge handbook of thinking and reasoning. Cambridge University Press; 2005. p. 633-661.A recent review of the language and thought literature, from a non-Whorfian perspective

Whorf, BL. Language, thought, and reality: Selected writings of Benjamin Lee Whorf. Carroll, JB., editor. MIT Press; Cambridge, Mass: 1956. A historical classic; one of the first important investigations of language and thought 

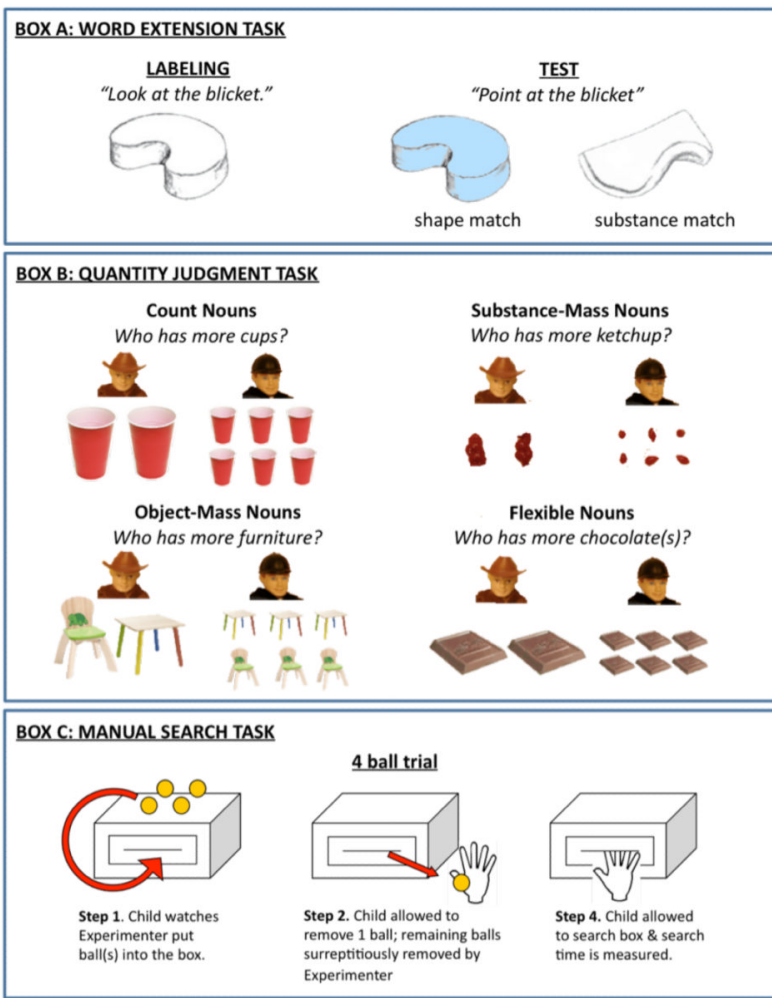

FIGURE 1.

Sketches of trials for word extension (BOX A), quantity judgment (BOX B), and the manual search task (BOX C) 